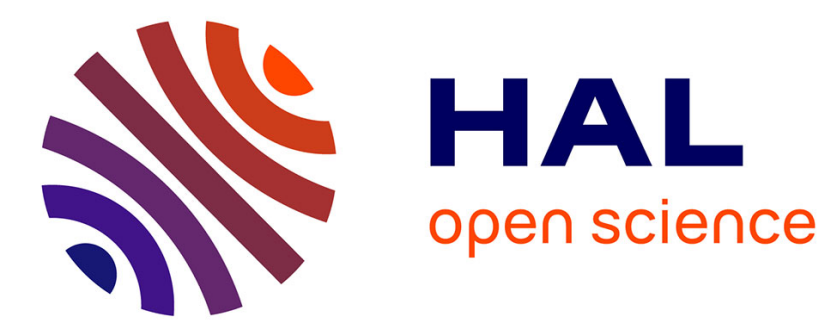

\title{
Combining climate and energy policies: synergies or antagonisms?
}

Oskar Lecuyer, Ruben Bibas

\section{To cite this version:}

Oskar Lecuyer, Ruben Bibas. Combining climate and energy policies: synergies or antagonisms?. FEEM Working Paper, 2011, pp.2011.98. hal-00801917

\section{HAL Id: hal-00801917 https: / hal-enpc.archives-ouvertes.fr/hal-00801917}

Submitted on 18 Mar 2013

HAL is a multi-disciplinary open access archive for the deposit and dissemination of scientific research documents, whether they are published or not. The documents may come from teaching and research institutions in France or abroad, or from public or private research centers.
L'archive ouverte pluridisciplinaire HAL, est destinée au dépôt et à la diffusion de documents scientifiques de niveau recherche, publiés ou non, émanant des établissements d'enseignement et de recherche français ou étrangers, des laboratoires publics ou privés. 


\title{
Combining climate and energy policies: synergies or antagonisms?
}

\author{
Oskar Lecuyer ${ }^{* \dagger \ddagger}$ and Ruben Bibas
}

\begin{abstract}
The European Union plans to include an energy efficiency binding target in addition to the renewables and $\mathrm{CO} 2$ targets. In this paper, we develop a requisite framework to study interactions arising from the combination of instruments aiming at reducing emissions, promoting renewables and energy efficiency. The model allows the exact assessment of the instruments interactions for quantities and prices. All instruments lead to emissions reductions and the carbon price gives the right incentives for renewable and energy efficiency. Contrary to these expected positive outcomes, we find that the combination of more than two instruments creates significant antagonisms regarding major policy objectives.
\end{abstract}

Keywords: Renewable energy, energy efficiency, energy policy, climate policy, policy interaction.

JEL Classification: Q28, Q41, Q48, Q58 


\section{Introduction}

The European Union (EU) has developed a climate and energy strategy with multiple objectives. Energy supply plays a central role in this strategy, not only for energy security concerns but mainly because it represents the largest opportunity for greenhouse gases (GHG) emissions mitigation. According to UNFCCC data UNFCCC (2011), the combustion of fossil fuels makes up for $88 \%$ of total EU GHG emissions.

The EU implemented in 2009 the Climate and Energy Package (CEP), aiming at (i) cutting GHG emissions by $20 \%$ compared to 1990 levels, (ii) producing $20 \%$ of its energy from renewable sources by 2020 UE (2009a,b,c) and (iii) increasing energy efficiency by $20 \%$. This last objective is not binding. Therefore, the EU plans to release a Directive on energy efficiency including binding measures for energy consumption reductions, among others UE (2011a,b). The CEP strengthens the European Emissions Trading Scheme (ETS), designed to share emissions reduction efforts among member states. For renewable energy, objectives are set at the state level, and most member states use a feed-in-tariff to reach it. Energy efficiency legislation is sector-oriented, due to the scattered nature of energy savings. Current legislation focuses on energy-intensive sectors such as buildings, manufacturing, energy transformation and transport.

Given the high degree of interdependency between emissions, various energy production sources and energy consumption reductions, interactions between those policies are inevitably significant. A wide range of research papers has investigated rationales, scope and conditions for efficient and effective policies to reduce GHG emissions, apart or in combination. A number of effects have been listed and characterized, but no formal definition of interactions has yet been formulated and microeconomic analysis of interactions between the objectives of the European Climate and Energy Package are still scarce.

This paper aims at helping bridging this gap. Its objective is to disentangle the role interactions can play in the performance of a policy combination by giving formal definition of interaction terms and quantifying them. We develop therefore a simple model of supplies and demand in the energy sector including the policy instruments of the CEP: a price on $\mathrm{CO}_{2}$ emissions, a renewable energy subsidy and various demand reduction instruments. In various policy combination scenarios we derive interaction terms between instruments.

Section 3 presents the model framework and analyzes interaction terms arising from the combination of several climate and energy policy instruments in several policy mix scenarii. Sections 4 and 5 discuss the results and conclude.

\section{Interactions and rationales for overlapping poli- cies}

The study of instrument combination is of particular interest in the energy sector. Regardless of the reason invoked for their implementation, climate and energy policy instruments affect energy-related goods that are highly substituable, emphasizing the importance ofinteractions and indirect effects of specific 
policies. In a very general sense, interactions can affect expected outcomes at any level: scope, objectives, implementation, operation or timing of a specific policy (Sorrell, 2003).

While each of these aspects is worth investigating for further insight in policy design, we will focus on a microeconomic perspective. This section discusses some issues in the economic study of climate and energy policy interactions and reviews some of the approaches adopted in the literature. For an exhaustive review of interaction studies and a general framework to assess potential effects of interaction between two instruments or two policy schemes, see for instance Oikonomou and Jepma (2008).

\subsection{Rationales for overlapping policies}

According to basic economic theory, a single $\mathrm{CO}_{2}$ price across the whole economy is the most efficient policy for mitigating emissions, because it allows for a first best allocation of resources. However this first-best regime refers to an ideal situation, because of several shortcomings in the emissions allowance market. Market failures, technological failures and externalities prevent the carbon market from reaching the right equilibrium. In the short term, the absence of transmission of $\mathrm{CO}_{2}$ price effects to end-users, imperfect foresight and bounded rationality can limit the efficiency and relevance of the emissions market. In the mid-term, security of supply concerns, imperfect competition and liquidity constraints can hinder the proper evolution of the permit price trajectory. In the long term, innovation failures, market power and market barriers limit the emergence of low carbon technologies.

Correcting each of these externalities or market failures is an objective as such. The so-called Tinbergen rule (Tinbergen, 1952) states that policy-makers should carry out an instrument for each one of its objective to avoid a trade-off that would favor one objective over another. Besides parallel achievement of different objectives, the joint implementation of policy instruments has been justified on several grounds:

- Induced technical change may be higher for some options than for others, justifying specific support (Philibert, 2011).

- The combination of inertia in technology deployment and imperfect foresight can justify implementing more costly options before the full potential for cheaper options is exhausted (Ha-Duong et al., 1997).

- Some market failures, regulatory failures or behavioural failures may reduce the economic efficiency of market-based instruments, justifying additional instruments to tackle them (Gillingham et al., 2009).

Regarding the CEP, the overlapping of policy instruments is supported by two alternative arguments. The first one places the climate mitigation objective as the main driver of economic changes, and other instruments are aimed at tackling the European ETS market failures. In this view, energy efficiency and renewable energy policies reduce knowledge-based and technology-based failures of specific low-carbon technologies. In the second view, several objectives 
are considered simultaneously. Reaching $20 \%$ of renewable energy production and $20 \%$ of energy consumption reductions are important as such because of additional benefits they bring along (e.g. local employment or the alleviation of energy security concerns). Yet, regardless of the adopted view, the interactions between European climate and energy policies are inevitably significant, given the high degree of interdependence between emissions, energy production sources and energy consumption reductions.

\subsection{Interactions resulting from policy overlapping}

There are several approaches in the literature on climate an energy policy interaction. Some authors classify interactions in different manners, mostly on the basis of effect on expected outcomes, scope and governance (Sorrell, 2003, Sorrell et al., 2003). Other analyze and sometimes quantify those effects, using analytical or numerical models (Abrell and Weigt, 2010, Skytte, 2006, Sorrell et al., 2009). A last category of papers uses a sectoral approach to highlight interaction, mainly in the electricity generation sector (Fischer and Preonas, 2010, Traber and Kemfert, 2009).

As defined by Sorrell (2003), a relevant distinction between direct and indirect interactions can be based upon the difference between affected and targeted groups. Direct interactions occur when groups targeted by two policy instruments overlap in some way. An indirect interaction takes place between two policy instruments when a target group is indirectly affected by one of the instruments, as when a renewable obligation on electricity producers and a tax on downstream electricity consumption both raise electricity price for end-users.

The INTERACT project report (Sorrell et al., 2003) makes further distinctions between internal and external interactions, and between vertical and horizontal interactions. Internal interactions refer to interactions between two or more climate policy instruments whereas external interactions refer to interactions between climate and non-climate policy instruments. Horizontal interactions refer to the same level of governance (the European level for instance) while vertical interactions refer to different levels. The report also defines trade policy interactions as the influence of one policy instrument on another by the exchange of an environmental trading commodity.

Analyzing mechanisms behind interactions, Skytte (2006) as well as Sorrell et al. (2009) develop graphical equilibrium analysis frameworks to separate effects in each considered market (environmental commodity, electricity or energy efficiency goods) and to distinguish effects on demand curve from effects on supply curve. They show in a graphical way that the promotion of one type of energy displaces demand and supply curves for all types of commodities, having an ambiguous effects on prices. Abrell and Weigt (2010) develop a static computable general equilibrium model of Germany with differentiated renewable technologies to test the effects of an emissions trading scheme and renewable support mechanisms on each other. Their study shows that adding an instrument promoting renewables to an ETS decreases environmental effectiveness by letting the carbon price drop to zero in some cases. This addition also decreases total welfare due to the additional financing needs of the renewable support 
scheme. This additional cost is highly sensitive on the learning rate assumptions for low carbon technologies. Numerical sectoral approaches, as developed by Traber and Kemfert (2009) allow a more specific discussion on supply technologies and a quantification of synergies between instruments. They show two frequently counteracting effects when combining an European ETS and national renewable promotion schemes: a substitution effect and a permit price effect. The latter occurs when substituting renewables to emitting fossil production. Increased renewable production then reduces total emissions, thus reducing the price of emissions permits and the end-user price. But promoting renewables substitutes to fossil energy a more expensive energy, increasing therefore the final price and leading to the substitution effect.

Fischer and Preonas (2010) develop a static partial equilibrium analytical framework enabling to analyze variations in quantities and prices when various policies are combined. Applying it to the American electricity production sector, they discuss perverse effects of the addition of an emissions cap or a renewable quota to a set of price-instruments (carbon tax, renewable subsidy or fossil fuel tax). The first major result is that overlapping price-instruments with an emissions cap can lead to the development of relative dirty technologies. When an emissions cap is in place, instruments raising the emissions permit price discourage dirty technologies, whereas instruments that lower the emissions price allow dirty technologies to displace cleaner ones ${ }^{4}$. In other terms, "when emissions are capped, none of the overlapping policies can simultaneously disadvantage both kinds of fossil generation" (Fischer and Preonas, 2010, p. 16). This meritorder effect has been previously described by Böhringer and Rosendahl (2009). The second major result is that when price instruments are combined to a renewable portfolio standard (RPS), any additional taxation of fossil energy will lower generation from renewable sources because of the market share constraint of the RPS.

\subsection{Motivation and contributions}

Most approaches tend to focus on graphical or qualitative approaches, or on specific interactions between two instruments, often the EU-ETS and an instrument promoting renewable energy. A comprehensive microeconomic approach of interactions between three objectives and three instruments is still lacking. This paper helps bridging the gap by analyzing interactions between all objectives of the Climate and Energy Package. We complement the previous approaches, more governance-oriented, by giving formal microeconomic definitions and analytical demonstrations of interaction effects. While simple on purpose, as it focuses on a deterministic, static partial equilibrium framework, we believe our methodology is a valuable tool to compare and assess effects of multiple instruments of the European climate and energy policy, in a context where binding targets may be voted for energy consumption reductions.

\footnotetext{
${ }^{4}$ But this displacement is only a second order effect. It does not affect the global amount of emissions.
} 


\section{A minimal microeconomic framework to analyze policy interactions}

This section presents the simple model developed to analyze interactions between climate and energy policies. The first subsection introduces the general framework and following subsections examine the different policy mix scenarii considered. Table 1 describes all four scenarii and the policy instruments included in each. Annex A lists all variables used in the model.

\subsection{Model framework}

Two fully substituable energies are combined to satisfy an exogenous demand in energy $(D)$ : the energy from fossil fuels $(f)$ and the energy from renewable sources $(r)$. This energy (in Joules or in MWh), is assumed to be consumed through a non-specified energetic vector, for instance electricity, in order to satisfy a service such as lighting, transportation or heating. The demand can be reduced by an amount $e$ through energy efficiency investments. This reduction refers to the production of the same energy service with a different efficiency. For instance, it can be the electricity savings following a switch to energy savings bulbs or a switch to an A+ labeled appliance. These reductions do not refer to sufficiency behaviors, where end-users adapt their consumption to price or specific programs. For a detailed discussion on the differences between efficiency and sufficiency, see Giraudet et al. (2011a,b). Sufficiency is represented by the decreasing slope of the net demand function. It represents all energy savings behavior components unrelated to technological improvement and which cannot be easily subsidized. Gross demand $D$ is defined by a function decreasing with the wholesale price $p$ (thus $D^{\prime}(p) \leq 0$ ). Demand is met according to following equation:

$$
f+r=D(p)-e
$$

The cost of producing energy from the two different sources $\left(C_{f}\right.$ and $\left.C_{r}\right)$ is assumed to be in both cases growing and convex $\left(C_{f}^{\prime}(f) \geq 0, C_{f}^{\prime \prime}(f)>0\right.$ and $C_{r}^{\prime}(r) \geq 0, C_{r}^{\prime \prime}(r)>0$, where $C_{i}^{\prime}=\frac{\partial C_{i}(i)}{\partial i}$ and $\left.C_{i}^{\prime \prime}(i)=\frac{\partial^{2} C_{i}(i)}{(\partial i)^{2}}\right)$. Decreasing returns can be justified by the adopted static framework. With a given technology mix and production capacity, each energy producer uses first the most efficient installations and moves gradually to costlier ones, according to merit order. Energy savings are provided by investments in energy efficiency, assumed to have also decreasing returns with respect to the energy savings, so for the same reason $C_{e}^{\prime}(e) \geq 0$ and $C_{e}^{\prime \prime}(e)>0$.

We consider four policy mix scenarii (cf. Table 1), including an instrument promoting energy efficiency, an instrument limiting GHG emissions and a renewable energy subsidy $(\rho)$ (for instance a feed-in tariff). Energy efficiency promoting instruments include a subsidy $(\varepsilon)$ and a quantitative energy efficiency target $(A)$ as in the French white certificate scheme, where participants must provide a certain amount of certificate at the end of each period. The white certificate are issued for each unit of energy saved compared to a baseline scenario. The future European directive under discussion considers to force the implementation of such a scheme in all member states. As further explained 


\begin{tabular}{|c|c|c|c|}
\hline Scenario & \multicolumn{3}{|c|}{ Policy instruments } \\
\hline $\mathrm{T}-\mathrm{S}$ & EE subsidy & Carbon tax & Renewable subsidy \\
\hline T-Q & EE quota & & \\
\hline $\mathrm{C}-\mathrm{S}$ & EE subsidy & Emission cap & \\
\hline $\mathrm{C}-\mathrm{Q}$ & EE quota & & \\
\hline
\end{tabular}

Table 1: Policy instruments included in the scenarii

in section 3.3, $\varepsilon$ then becomes analogous to dual variable and can be used as a proxy for the price of white certificates used on the energy efficiency market associated to the constraint. GHG limiting instruments include a carbon tax $(\phi)$ and a cap-and-trade system . As we model a perfect market in a world without uncertainty, this latter is equivalent to a tax equal to the price of emissions permits. We therefore limit our study of scenarii including a cap-and-trade system to the interactions between renewable energy and energy efficiency instruments with the certificate price.

The two energies and the energy-efficient good to reduce demand are produced by representative producers, assumed to be price-takers and satisfying the following symmetric profit-maximization programs:

$$
\begin{array}{cl}
\max _{f} \pi_{f}=(p-\phi) \cdot f-C_{f}(f) & \text { for production from fossil source } \\
\max _{r} \pi_{r}=(p+\rho) \cdot r-C_{r}(r) & \text { for production from renewable source } \\
\max _{e} \pi_{e}=(p+\varepsilon) \cdot e-C_{e}(e) & \text { for energy savings from efficient goods }
\end{array}
$$

with $f, r, e \geq 0$ and $p$ the wholesale price. In this setting, the price is the wholesale market price. It comprises neither price instruments nor the public cost of the policy. For simplicity, we consider energy efficiency as an energy good. It means that we only consider the final savings of efficient goods and tune the cost curve accordingly.

When replacing an old refrigerator for example, the choice is between taking an average-rated one or a more efficient one. The cost difference between both can be here seen as an energy efficiency investment. This investment leads to a saving corresponding to the consumption difference between both appliances during a given time. Considering energy efficiency in this way allows the development of a quasi-symmetric framework useful to apprehend interaction effects. The cost function $C_{e}(e)$ thus gives the portion of the total cost of a given efficient good corresponding to the energy savings.

\subsection{Scenario T-S: carbon tax and energy efficiency subsidy}

We compute the total differentials of the market equilibrium equations derived from the first-order conditions of the profit-maximization programs (2), (3), (4) and the demand constraint (1). It results in following system allowing us to study instantaneous and infinitesimal variations of wholesale price, energy quantities and energy savings around the equilibrium: 
System 1 (Price and quantity differentials in scenario T-S).

$$
\begin{aligned}
d p & =(d f+d r+d e) / D^{\prime}(p) \\
d f & =(d p-d \phi) / C_{f}^{\prime \prime}(f) \\
d r & =(d p+d \rho) / C_{r}^{\prime \prime}(r) \\
d e & =(d p+d \varepsilon) / C_{e}^{\prime \prime}(e)
\end{aligned}
$$

Solving this system for $d f, d r$, de and $d p$, gives following equations, describing variations in wholesale price, energy quantities and energy savings as a function of the various policy changes:

Result 1 (Differentials with respect to instrument levels in scenario T-S).

$$
\begin{aligned}
& d f=\frac{-d \phi \cdot\left(\eta_{f} \eta_{r}+\eta_{f} \eta_{e}+\eta_{f} \eta_{D}\right)-d \rho \cdot \eta_{f} \eta_{r}-d \varepsilon \cdot \eta_{f} \eta_{e}}{\eta_{f}+\eta_{r}+\eta_{e}+\eta_{D}} \\
& d r=\frac{d \rho \cdot\left(\eta_{r} \eta_{f}+\eta_{r} \eta_{e}+\eta_{r} \eta_{D}\right)+d \phi \cdot \eta_{r} \eta_{f}-d \varepsilon \cdot \eta_{r} \eta_{e}}{\eta_{f}+\eta_{r}+\eta_{e}+\eta_{D}} \\
& d e=\frac{d \varepsilon \cdot\left(\eta_{e} \eta_{f}+\eta_{e} \eta_{r}+\eta_{e} \eta_{D}\right)+d \phi \cdot \eta_{e} \eta_{f}-d \rho \cdot \eta_{e} \eta_{r}}{\eta_{f}+\eta_{r}+\eta_{e}+\eta_{D}} \\
& d p=\frac{d \phi \cdot \eta_{f}-d \rho \cdot \eta_{r}-d \varepsilon \cdot \eta_{e}}{\eta_{f}+\eta_{r}+\eta_{e}+\eta_{D}}
\end{aligned}
$$

where $\eta_{i}$ (with $i \in\{f, r, e\}$ ) is defined as $\eta_{i}=\frac{1}{C_{i}^{\prime \prime}} \geq 0$ and corresponds to the derivative of the inverse supply function with respect to price $\eta_{i}=1 / C_{i}^{\prime \prime}(q)=$ $\left(C_{i}^{\prime-1}\right)^{\prime}\left(p+\alpha_{i}\right)$ for both energy types and the energy savings, with $\alpha_{i}$ referring to price instruments $\left(\alpha_{i} \leq 0\right.$ for taxes and $\alpha_{i} \geq 0$ for subsidies). The inverse supply function corresponds to the marginal cost curve if we consider a pure competition framework with price-taking producers. $\eta_{D}$ is defined as $\eta_{D}=$ $-D^{\prime}(q) \geq 0$ in order to have a positive variable and facilitate the comparison with marginal cost curve derivatives.

In (9), (10), (11) and (12), the coefficient of policy variables $d \phi, d \rho$ and $d \varepsilon$ corresponds to the partial derivatives of respective quantity or price variables with respect to corresponding policy variable. For instance, in (9), the coefficient of $d \phi$ corresponds to the partial derivative of fossil production with respect to carbon tax, $\frac{\partial f}{\partial \phi}=\frac{-\left(\eta_{f} \eta_{r}+\eta_{f} \eta_{e}+\eta_{f} \eta_{D}\right)}{\eta_{f}+\eta_{r}+\eta_{e}+\eta_{D}}$. It corresponds to the variation of fossil production when the carbon tax is changing.

In this example, the partial derivative is negative, meaning that increasing the carbon tax reduces energy production from fossil fuel at equilibrium. This is due to several effects. Increasing the tax increases the marginal cost of producing energy from fossil fuel. This increase shifts the supply curve $C_{f}^{\prime-1}(p-\phi)$ downwards (because it is an increasing function), raising the price at equilibrium. This shift is characterized by expression $-\eta_{f} \eta_{D}$ in (9), corresponding to the product of fossil energy supply curve and the opposite demand curve. An increase in $\phi$ will also have an effect on $\eta_{f}$ itself, indirectly changing the slope of the supply curve. If $C_{f}^{\prime \prime}$ is increasing with respect to production, the partial derivative of the fossil energy supply curve with respect to carbon tax is negative: $\frac{\partial C_{f}^{\prime-1}(p-\phi)}{\partial \phi}=\frac{-1}{C_{f}^{\prime \prime}\left(C_{f}^{-1}(p-\phi)\right)} \leq 0$. The decreasing slope of the supply curve adds up to the downward shift. 


\begin{tabular}{ccccc}
\hline & $d f$ & $d r$ & $d e$ & $d p$ \\
\hline$d \phi$ & - & + & + & + \\
$d \rho$ & - & + & - & - \\
$d \varepsilon$ & - & - & + & - \\
\hline
\end{tabular}

Table 2: Signs of the partial derivatives of both energy types $(f, r)$, energy savings $(e)$ and market price $(p)$ with respect to the policy instrument levels $(\phi, \rho$ and $\varepsilon)$ in scenario T-S.

An increase in $\phi$ also reduces the relative cost of renewable energy and energy savings compared to energy from fossil fuel. The change in relative costs induces a substitution between fossil energy and the two other energy options, renewable energy and energy efficiency. This substitution is characterized by expressions $-\eta_{f} \eta_{r}$ and $-\eta_{f} \eta_{e}$ in (9). The analogous expressions can be found in (10) and (11). All above effects are tempered by the sum of all supply curves and the demand curve. The substitutions and this tempering can be seen as a first effect of instrument combination.

Table 2 summarizes the signs of the partial derivatives of both energy types $(f, r)$, energy savings $(e)$ and market price $(p)$ with respect to the policy instrument levels $(\phi, \rho$ and $\varepsilon)$. For instance, a - sign on the intersection of column $d f$ and line $d \phi$ means that $\frac{\partial f}{\partial \phi}$ is negative, an increase in $\phi$ comes with a decrease in $f$ at equilibrium. The rate of variation of the market price is negative with respect to subsidies $\rho$ and $\varepsilon$ because we do not consider the funding of those policy instruments.

Equations (9), (10), (11) and (12) can also be interpreted as a whole, interpreting the effect on price or production of a combined change of two separate instrument levels. A simultaneous increase of $\phi, \rho$ and $\varepsilon$ will have negative effects on fossil energy production that add up. Similarly, an increase in both $\phi$ and $\varepsilon$ will have two positive effects on energy savings that add up. By contrast, an increase in both $\rho$ and $\varepsilon$ will have an ambiguous effect on renewable production, as the two effects have opposite signs. In this framework, we can give following definitions:

Definition 1 (synergy). Two policy instruments are in synergy with respect to a given variable (like production or price) when the partial derivative of this variable with respect to the policy instruments have the same sign.

Definition 2 (antagonism). Two policy instruments are in synergy with respect to a given variable (like production or price) when the partial derivative of this variable with respect to the policy instruments have opposite sign.

Here, subsidies for renewable energy and energy savings are antagonistic for renewable production and energy savings. A simultaneous increase in the level of the subsidies will result in an ambiguous effect on renewable production and on savings resulting from energy efficiency. Similarly, the carbon tax and the subsidy for either renewable production or energy savings are in synergy for respectively either renewable production and emissions reductions or energy savings and emissions reductions. They are antagonistic for respectively either 
energy savings and emissions reductions or renewable production and emissions reductions. Table 2 shows also that subsidies for renewable production and energy savings are in synergy with respect to the wholesale price, as both tend to reduce it, whereas there is an antagonism between those instruments and the carbon tax with repsect to the wholesale price. This is due to the fact that for simplicity we did not consider the impact of price instruments on the public finances.

\subsection{Scenario T-Q: carbon tax and energy efficiency target}

In this scenario, the subsidy on energy efficiency is replaced by a quantitative target. To represent an energy efficiency target, we assume that all accountable reductions are made through energy efficiency investments. This is true for instance for the French white certificate scheme, where certificate are issued on the basis of standard procedures such as the replacement of an appliance. Additional consumption reduction can be the result of sufficiency behaviors. Those reductions are however difficult to account for. In the present setting, they are captured by the decreasing slope of the demand curve, or a possible shift to the left. Change in the energy price resulting from various policies can also lead to a rebound effect. A demand reduction will induce a price drop that itself lead to an demand increase.

For simplicity, we therefore display an energy efficiency target as a demand reduction requirement $e^{\star}$, corresponding to a certain percentage of total consumption. Global energy demand has to be lowered by a certain percentage $A$ compared to the business-as-usual scenario. We moreover assume that the quota is binding. By doing so, we simply assume $C_{e}$ is bigger than $C_{r}$ and $C_{f}$ : other energy types are cheaper. This seems reasonable, otherwise promotion of energy efficiency would be unnecessary.

In the equations, all goods are linked by the quota constraint : $e=A D(p)=$ $A(f+r+e)$. Totally differentiating this constraint, system (1) becomes:

System 2 (Price and quantity differentials in scenario T-Q).

$$
\begin{aligned}
d p & =(d f+d r+d e) / D^{\prime}(p) \\
d f & =(d p-d \phi) / C_{f}^{\prime \prime}(f) \\
d r & =(d p+d \rho) / C_{r}^{\prime \prime}(r) \\
d e & =\frac{A}{1-A}(d f+d r)+\frac{d A}{1-A}(f+r+e)
\end{aligned}
$$

The system is resolved with following outcome:

Result 2 (Differentials with respect to instrument levels in scenario T-Q).

$$
\begin{aligned}
d f & =\frac{-d \phi \cdot\left(\eta_{f} \eta_{r}+\eta_{f}(1-A) \eta_{D}\right)-d \rho \cdot \eta_{f} \eta_{r}-d A \cdot \eta_{f} \cdot D(p)}{\eta_{f}+\eta_{r}+(1-A) \eta_{D}} \\
d r & =\frac{-d \rho \cdot\left(\eta_{r} \eta_{f}+\eta_{r}(1-A) \eta_{D}\right)-d \phi \cdot \eta_{f} \eta_{r}-d A \cdot \eta_{r} \cdot D(p)}{\eta_{f}+\eta_{r}+(1-A) \eta_{D}} \\
d e & =\frac{d \phi \cdot A \eta_{f} \eta_{D}-d \rho \cdot A \eta_{r} \eta_{D}+d A \cdot D(p) \cdot\left(\eta_{f}+\eta_{r}+\eta_{D}\right)}{(1-A) \eta_{D}+\eta_{f}+\eta_{r}}
\end{aligned}
$$




\begin{tabular}{cccccc}
\hline & $d f$ & $d r$ & $d e$ & $d p$ & $d \varepsilon$ \\
\hline$d \phi$ & - & + & + & + & - \\
$d \rho$ & - & + & - & - & + \\
$d A$ & - & - & + & - & + \\
\hline
\end{tabular}

Table 3: Signs of partial derivatives of variables $(f, r, e, p)$ and certificate shadow price $(\varepsilon)$ with respect to instrument levels $(\phi, \rho$ and $A)$ in scenario T-Q.

$$
d p=\frac{d \phi \cdot \eta_{f}-d \rho \cdot \eta_{r}-d A \cdot D(p)}{\eta_{f}+\eta_{r}+(1-A) \eta_{D}}
$$

This result can be analyzed in the same way as the previous one. In (17), (18), (19) and (20), the coefficients of $d \phi, d \rho$ and $d A$ correspond to the partial derivatives of price and quantities with respect to the policy instrument. Compared to scenario T-S, the addition of a consumption reduction quota simplifies the system by removing some of the substitutions. This is due to the additional constraint, linking the energy savings to total demand, and reducing the number of variables in the system. With this binding constraint, the variations of $e$ are due to the variation of the global energy demand, and can be seen as a shift along the demand curve (expressions $\left(A \eta_{f} \eta_{D}\right)$ and $\left(-A \eta_{r} \eta_{D}\right)$ in (19)). This effect is tempered by some substitutions between $e$ and $r$, and between $e$ and $f$, at a level depending on the relative slopes of inverse demand functions. Equations (17) and (18) thus display only one substitution term, similar to the corresponding one in (19).

The addition of a consumption reduction quota affects the slope of the demand curve. The quota permanently reduces the demand and $\eta_{D}$ is replaced by $(1-A) \eta_{D}$. This change of the demand curve slope has an effect on energy production when the quota $A$ is moving. An increase in the quota level rises the energy savings compared to renewable and fossil energy productions $\left(\frac{\partial f}{\partial A} \leq 0\right.$ and $\left.\frac{\partial r}{\partial A} \leq 0\right)$. The effect on the wholesale price follows this move of the demand curve and decreases too, at a rate proportional to BAU demand (i.e. the demand without the savings).

Table 3 summarizes the signs of rates of variations of both energy types $(f, r)$, energy savings $(e)$, market price $(p)$ and certificate shadow price $(\varepsilon)$ with respect to policy instrument levels $(\phi, \rho$ and $A)$. The certificate shadow price is defined in the next section. Results are comparable as those presented in Table 2. The effects of a small change in the quota $A$ have the same sign than the effects of a change in energy savings subsidy in the previous section. The magnitude of these effects changes however, depending this time on the absolute level of demand. In addition to antagonisms and synergies highlighted in Table 2 , we show here the counteracting effects of respectively renewable subsidy and carbon tax or energy savings subsidy and carbon tax on the certificate price $\varepsilon$ (as described in section 3.4). 


\subsection{Scenario T-Q: effects on the energy efficiency certificate price $(\varepsilon)$}

With a consumption reduction quota, $\varepsilon$ becomes a shadow price, that is an indication of the price of a white certificate if the consumption reduction quota is backed by a certificate market. It can be seen as an addition to the wholesale price for the energy savings, in order to help them become competitive compared to energy production. Formally, it corresponds to the spread between the wholesale price $p$ and the marginal cost of energy savings $C_{e}^{\prime}$. Replacing $d e, d f, d r$ in the quota constraint (16) and solving for $d \varepsilon$ gives:

Result 3 (Certificate price differential in scenario T-Q).

$$
d \varepsilon=\frac{d \rho \cdot\left(\eta_{r}\left(\eta_{e}+A \eta_{D}\right)\right)-d \phi \cdot\left(\eta_{f}\left(\eta_{e}+A \eta_{D}\right)\right)+d A \cdot D(p)\left(\eta_{e}+\eta_{f}+\eta_{r}+\eta_{D}\right)}{\eta_{f} \eta_{e}+\eta_{r} \eta_{e}+(1-A) \eta_{e} \eta_{D}}
$$

Changes in the carbon tax or the renewable subsidy will cause some substitutions between fossil and renewable energy, and move the equilibrium price. An increase in renewable subsidy $d \rho$ will raise the certificate price, by increasing the spread between wholesale price and marginal cost of energy savings. On the contrary, the carbon tax, by raising the wholesale price $p$ decreases this spread and causes the certificate price to fall.

A change in the quota level $d A$ first moves the demand curve, causing the wholesale price to drop, and consequently the certificate price to raise. Second, it causes the relative share of the energy savings to raise compared to renewable and fossil energy, leading to an increase of the marginal cost of energy savings, and thus an increase in $\varepsilon$. It is noteworthy that when an energy efficiency quota is in place, the energy savings cost curve has no impact on the equilibrium any more.

\subsection{Scenarii C-S and C-Q: addition of energy efficiency instru- ments to a $\mathrm{CO}_{2}$ cap}

This framework also allows to analyze impacts of instrument combination on the ETS permit price. In order to do so, we assume the cap is binding, and thus emissions and fossil production are fixed: $d f=0$. In this setting, $\phi$ becomes the shadow price of the emissions constraint, equal to the absolute value of the spread between market price and the marginal cost of producing energy from a fossil fuel. $\phi$ can be interpreted as a proxy of the ETS permit price. The effect of changes in renewables and energy efficiency instruments on the permit price is summarized in Table 4.

\subsubsection{Scenario C-S: $\mathrm{CO}_{2}$ cap and EE subsidy}

By substituting $d f$ from (9) and resolving for $d \phi$, we obtain:

Result 4 (emissions permit price differential in scenario C-S).

$$
d \phi=-d \rho \frac{\eta_{r}}{\eta_{r}+\eta_{e}+\eta_{D}}-d \varepsilon \frac{\eta_{e}}{\eta_{r}+\eta_{e}+\eta_{D}}
$$




\begin{tabular}{llll}
\hline & $d \rho$ & $d \varepsilon$ & $d A$ \\
\hline$d \phi$ & - & - & - \\
\hline
\end{tabular}

Table 4: Signs of rate of variations of $\mathrm{CO}_{2}$ permit price $(\phi)$ with respect to policy instrument levels $(\varepsilon, \rho$ and $A$ ) in scenarii C-S and C-Q.

We see that an increase in either the renewable or the energy savings subsidy has a negative impact on the emissions permit price, weighted by a ratio denoting the substitution between fossil energy and alternatives to fossil energy when they are subsidized. When for instance renewable energy is subsidized, it increases its market share compared to fossil energy. This reduces the burden on fossil energy producers, it is less costly to comply with the emissions quota and the permit price drops.

This result illustrates the recent debate about the necessity to "set aside" some of the emissions permits in parallel of implementing energy-efficiency measures, in order to prevent the carbon price to collapse. An increased objective on renewable energy production or energy savings would put a downward pressure on carbon price, weakening the price signal given to the whole economy.

\subsubsection{Scenario $\mathrm{C}-\mathrm{Q}: \mathrm{CO}_{2}$ cap and $\mathrm{EE}$ quota}

With an energy savings quota, $d \phi$ can be derived from (17), giving following equation:

Result 5 (emissions permit price differential in scenario C-Q).

$$
d \phi=-d \rho \frac{\eta_{r}}{\eta_{r}+(1-A) \eta_{D}}-d A \frac{D(p)}{\eta_{r}+(1-A) \eta_{D}}
$$

The results are comparable to the situation with only price instruments. An increase in the energy savings quota will have a negative influence on the emissions permit price. This time only, the magnitude of the influence is proportional to total demand and not the slope of the curve, resulting in a potentially larger effect on permit price.

\section{Summary of results and discussion}

Regarding the primary objective of the European climate and energy strategy, namely the reduction of GHG emissions, the model shows that all the instruments considered unequivocally reduce fossil energy consumption and therefore associated GHG emissions (see Tables 2 and 3). The impact of the different instruments on the wholesale price is however variable. If the impact on public finance is overlooked and no charge is put on end-users, a carbon tax will raise the price with the emissions reductions whereas renewable and energy savings subsidies lower it.

The interaction between emissions permit price and subsidies for renewable energy production or energy savings is shown to be negative. At equilibrium, the 
two subsidies reduce the emissions permit price. If the existence of a significant emissions price is considered an objective in itself, this could lead to a serious loss of global efficiency for the policy package on the long term. The perspective of a strengthening of the renewable production objective or the energy efficiency target has already had a negative impact on the forward ETS price. As widely discussed in the press and the economic literature, a set-aside of some of the emissions permits would be a way to keep the market under pressure and would help reduce regulatory uncertainty about future levels of $\mathrm{CO}_{2}$ price.

Regarding all objectives of the Climate and Energy Package, the model shows that a carbon tax promotes at the same time the reduction of fossil energy consumption, the development of renewable energy and consumption reductions through energy efficiency investments. In the presence of substantial objectives for renewables and energy savings, this instrument may however not be sufficient. It only ensures renewable energy and consumption reductions evolve in the right direction, not that they will reach a specified target. Instruments specifically promoting renewables and energy efficiency have to be added to the system to ensure renewable production is above and energy consumption below targeted levels. When they are implemented together, the two subsidies have however opposite effects on productions and tend to reduce the absolute level of each other.

We give a formal definition of synergistic and antagonistic effects in the model. Two policy instruments have antagonistic effects with respect to a given variable (like production or price) when their partial derivative with respect to this variable have opposite signs. Two policy instruments are in synergy when those partial derivatives have the same sign. When they are implemented together, a carbon tax, a renewable subsidy and an energy savings subsidy have antagonistic effects with respect to market price. The two subsidies are antagonists with respect to renewable production and energy savings. The promotion of renewables comes at the expense of energy savings promotion and conversely.

According to the model, the addition of a consumption reduction quota or a white certificate scheme has, as one could expect, positive effects on the demand, by reducing the net demand curve and reducing its slope. By reducing the net demand, the energy savings quota reduces the need for fossil energy (and thus GHG emissions) and reduces the market price. Moeover an energy efficiency quota reduces the slope of the net demand curve. But energy efficiency investments are in competition with renewables and in the model, an increase of the quota comes with a decrease in renewable production at equilibrium. Furthermore, an increase of the consumption reduction quota is followed by a decrease in carbon price. This decrease is proportional to total demand, resulting in a potentially large effect on permit price.

Since the model is static, it overlooks important dynamic effects such as inertia or technical change. Yet, in the energy sector, a static analysis makes sense for several reasons. First, the capital-intensive nature of the energy sector, coupled with the imperfections in investors' expectations stresses the importance of short-term signals for investment decisions. Regulatory uncertainty is perceived as a major risk for investors, thus un- derstanding interaction between those signals at the investors' time scale is crucial. Moreover, long-term signals emerge from the interactions of short-term effects, and most analysis dealing 
with optimal mix of energy sources implicitly assume that short-term marginal costs equal long-term maginal costs.

Another major assumption of the model is the perfect subsituability between renewable energy and energy efficiency. This is true with regards to some objectives, such as meeting the energy demand, the reduction of fossil fuel consumption or the reduction of GHG emissions. Being in the top-priority list of the EU strategy, linking those policies and the targets associated stands to reason. To be fully effective, policies such as the improvement of energy security or the fight against climate change should consider all antagonistic effects of a simultaneous promotion of energy efficiency and renewable energy or develop a single instrument to reach its objective with less risks and less uncertainty.

However, in many other aspects, renewable energy and energy efficiency are rather complementary. Renewables are supply-side oriented whereas energy efficiency has a huge potential on the end-user side. Energy savings often min- gle technology-based energy efficiency improvements with behavioral-based energy sufficiency improvements. While both tend to save energy, their promotion is obviously very differ- ent in nature, involving information campaigns and indirect incentives in the latter case. The promotion of technology- based energy efficiency can also take many forms, ranging from R\&D subsidies to training programs for building sector workers or cross-incentive reductions.

\section{Conclusion}

In order to analyze interaction effects between instruments of the European Climate and Energy Package, we develop in this paper a stylized analytical framework of the energy sector. This framework allows to compare and quantify interactions of various nature on prices and quantities. We use it to give a formal definition of synergistic and antagonist interaction effects. We discuss the potential effects of future mandatory instruments of the draft Energy Efficiency Directive. We show that regarding the objective of GHG emissions reductions all instruments are effective, but that major antagonisms arise when several objectives are considered concerning wholesale power price and emissions allowance price as well as renewable energy production and energy savings levels.

In a very broad sense, one instrument allows to control the absolute production of one energy type, but it only ensures that alternative energy types evolve in the right direction. Additional instruments are needed to control the absolute production from several energy sources at the same time, but at the expense of possible antagonisms between instruments. With three constraints, as considered in this model, it is possible to control the absolute production from three energy sources. The absolute level of price can be controlled, but at the expense of loosing the control on the production level from one energy source. In the existence of an objective on the energy price level (for distributional or political purpose for example) or on the carbon price, an additional constraint is necessary, but is likely to have a significant effect on welfare.

In our model, a single carbon price allows the reduction of fossil fuels. Additional measures are necessary to ensure renewable energy and energy consump- 
tion reductions are above targeted levels. Those additional measures reduce the efficiency of any instrument taken independently. Setting a price on renewable energy or energy efficiency promotion reduces the carbon price, and thus the incentive of carbon-free economy-wide investments (other than those promoted by the policies considered). The joint promotion of renewable energy and energy efficiency has antagonist effects by substituting renewables to energy savings and conversely. This corroborates current concerns about a future carbon price drop following the tightening of renewable or energy efficiency development objectives.

We also model the introduction of a quantitative binding consumption reduction target. We show that by reducing the net demand, the energy efficiency quota reduces GHG emissions and reduces the market price. This leads however again to antagonistic effects with instruments promoting renewables. Despite having several positive effects on its own (like lower dependency on energy imports, lower future capital-intensive investment needs and additional positive externalities such as local employment), a demand reduction instrument may not be compatible with other instruments in the Climate and Energy Package.

The existence of these interactions suggests the need for an integrated approach of climate and energy policy definition. The objectives have to be tuned together, and instrument levels have to be defined taking into account all other instruments. Put in other words, when adding a binding instrument to the existing climate and energy instrument pool, those existing instruments should be assessed and reviewed accordingly. If considered important, the price reduction objective, a European priority not so long ago (along with the energy markets liberalization), should also be integrated into the policy design process and should be adressed with a specific instrument.

Bearing in mind that the devils is in the details and that a detailed assessment of specific instruments have to be done, one should consider our methodology for assessing climate and energy policy packages at a macroeconomic level.

\section{Acknowledgments}

We thank Philippe Quirion and Adrien Vogt-Schilb for their useful comments and suggestions. This work as benefited from presentation feedbacks from participants at the 23rd International Climate Policy Workshop in the University of Malta, at the annual conference of the French Association of Energy Economists 2011, at internal seminars at EDF R\&D energy economics department (EDF R\&D EFESE) and at internal seminars at CIRED. Funding for this project was provided by EDF R\&D and the CIRED.

\section{References}

Abrell, J. and Weigt, H. (2010). The interaction of emissions trading and renewable energy promotion. Economics of Global Warming WP-EGW-05, Dresden University of Technology, Dresden, Germany. http://ssrn.com/abstract= 1317310. 
Böhringer, C. and Rosendahl, K. E. (2009). Green serves the dirtiest. on the interaction between black and green quotas. Discussion Papers 581, Research Department of Statistics Norway.

Fischer, C. and Preonas, L. (2010). Combining policies for renewable energy: Is the whole less than the sum of its parts? International Review of Environmental and Resource Economics, 4:51-92.

Gillingham, K., Newell, R. G., and Palmer, K. (2009). Energy efficiency economics and policy. Discussion Paper 09-13, Resources for the Future, Washington, DC. Forthcoming in the Annual Review of Resource Economics.

Giraudet, L.-G., Guivarch, C., and Quirion, P. (2011a). Comparing and combining energy saving policies: Will proposed residential sector policies meet french official targets? The Energy Journal, 0(Special I).

Giraudet, L.-G., Guivarch, C., and Quirion, P. (2011b). Exploring the potential for energy conservation in french households through hybrid modeling. Energy Economics, (0):--

Ha-Duong, M., Grubb, M., Hourcade, J., et al. (1997). Influence of socioeconomic inertia and uncertainty on optimal co2-emission abatement. Nature, 390(6657):270-273.

Oikonomou, V. and Jepma, C. (2008). A framework on interactions of climate and energy policy instruments. Mitigation and Adaptation Strategies for Global Change, 13(2):131-156.

Philibert, C. (2011). Interactions of policies for renewable energy and climate. IEA working paper, InternatIonal energy agency.

Skytte, K. (2006). Interplay between environmental regulation and power markets. EUI-RSCAS Working Papers 4, European University Institute (EUI), Robert Schuman Centre of Advanced Studies (RSCAS).

Sorrell, S. (2003). Carbon trading in the policy mix. Oxford Review of Economic Policy, 19(3):420-437.

Sorrell, S., Harrison, D., Radov, D., Klevnas, P., and Foss, A. (2009). White certificate schemes: Economic analysis and interactions with the EU ETS. Energy Policy, 37(1):29 - 42.

Sorrell, S., Smith, A., Betz, R., Walz, R., Boemare, C., Quirion, P., Sijm, J. Konidari, D. M. P., Vassos, S., Haralampopoulos, D., and Pilinis, C. (2003). Project INTERACT: Interaction in EU climate policy. FINAL REPORT EVK2-CT-2000-0067, SPRU.

Tinbergen, J. (1952). On the Theory of Economic Policy. Amsterdam, Netherlands: North-Holland.

Traber, T. and Kemfert, C. (2009). Impacts of the german support for renewable energy on electricity prices, emissions, and firms. the energy journal, $30(3): 155-178$. 
UE (2009a). Decision on the effort of member states to reduce their greenhouse gas emissions to meet the community's greenhouse gas emission reduction commitments up to 2020. Decision 406/2009/EC, European Parliament and Council.

UE (2009b). Directive amending directive 2003/87/ec so as to improve and extend the greenhouse gas emission allowance trading scheme of the community. Directive 2009/29/EC, European Parliament and Council.

UE (2009c). Directive on the promotion of the use of energy from renewable sources and amending and subsequently repealing directives 2001/77/ec and 2003/30/ec. Directive 2009/28/EC, European Parliament and Council.

UE (2011a). Energy efficiency plan 2011. Communication from the Commission COM(2011) 109 final, European Commission.

UE (2011b). Proposal for a directive on energy efficiency and repealing directives 2004/8/ec and 2006/32/ec. Proposal COM(2011) 370 final, European Parliament and Council.

UNFCCC (2011). Greenhouse gas inventory data. http://unfccc.int/ghg_data/ items/3800.php.

\section{A List of variables}

\begin{tabular}{ll}
\hline List & of variables \\
\hline$f$ & Fossil energy \\
$r$ & Renewable energy \\
$e$ & Energy savings \\
$p$ & Wholesale price \\
$D$ & Energy demand \\
$C_{i}$ & Cost curve for energetic good $i$ \\
$C_{i}^{\prime}$ & Marginal cost curve for good $i$ \\
$C_{i}^{\prime \prime}$ & Marginal cost curve variation for $i$ \\
$\eta_{i}$ & Slope of the supply curve of good $i$ \\
$\eta_{D}$ & Opposite of the demand curve slope \\
$\phi$ & Carbon tax \\
$\rho$ & Renewable energy subsidy \\
$\epsilon$ & Energy savings subsidy \\
$A$ & Consumption reduction quota \\
$d \alpha$ & Small variations of variable $\alpha$ \\
\hline &
\end{tabular}

